\title{
Patent portfolio analysis of cities: statistics and maps of technological inventiveness
}

\section{Dieter Franz Kogler, Gaston Heimeriks \& Loet Leydesdorff}

To cite this article: Dieter Franz Kogler, Gaston Heimeriks \& Loet Leydesdorff (2018) Patent portfolio analysis of cities: statistics and maps of technological inventiveness, European Planning Studies, 26:11, 2256-2278, DOI: 10.1080/09654313.2018.1530147

To link to this article: https://doi.org/10.1080/09654313.2018.1530147

\section{Published online: 29 Oct 2018.}

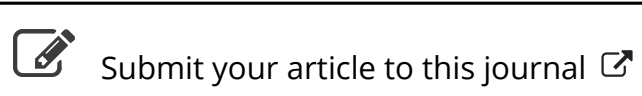

Џll Article views: 34

View Crossmark data ¿ 


\title{
Patent portfolio analysis of cities: statistics and maps of technological inventiveness
}

\author{
Dieter Franz Kogler (D) ${ }^{a}$, Gaston Heimeriks (D) $^{b}$ and Loet Leydesdorff (D) \\ aSpatial Dynamics Lab, School of Architecture, Planning \& Environmental Policy, University College Dublin, \\ Dublin 4, Ireland; ${ }^{b}$ Innovation Studies, Copernicus Institute of Sustainable Development, Utrecht University, \\ Utrecht, The Netherlands; ${ }^{c}$ Amsterdam School of Communication Research (ASCoR), University of Amsterdam, \\ Amsterdam, The Netherlands
}

\begin{abstract}
Cities can be considered as engines of the knowledge-based economy, because they are the primary sites of knowledge production activities that subsequently shape the rate and direction of technological change and economic growth. Patents provide rich information to analyse the knowledge specialization of specific places, such as technological details and information on inventors and entities involved. The technology codes attributed at the level of individual patent documents can be used to indicate the diversity and scope of the knowledge claims underlying a specific invention. In this study we introduce tools for portfolio analysis in terms of patents that provide insights into the technological specialization of cities. The mapping and analysis of patent portfolios of cities exploits data derived from the Unites States Patent and Trademark Office (USPTO) and dedicated tools (at https://leydesdorff.net/software/patents/). The results allow policy makers and other stakeholders to identify promising areas of further knowledge development, including smart specialization strategies.
\end{abstract}

\section{ARTICLE HISTORY}

Received 15 March 2018

Accepted 28 September 2018

\section{KEYWORDS}

Knowledge production; technological change;

knowledge space; patent

analysis; invention;

agglomeration;

specialization; diversity; cities

\section{JEL CODES}

011;031; 034

\section{Introduction}

Cities with their dense mixtures of people and economic activities can be considered as prominent locations of knowledge production and innovation (Bairoch, 1988; Bettencourt, Lobo, Helbing, Kühnert, \& West, 2007; Carlino, Chatterjee, \& Hunt, 2007; Jacobs, 1969). While there has been significant attention for the process of knowledge production in regional and national innovation systems (Feldman \& Kogler, 2010), with some exceptions little consideration has been given to the knowledge produced at specific places (Kogler, Essletzbichler, \& Rigby, 2017; Kogler, Rigby, \& Tucker, 2013). This is a pressing issue because technological knowledge production is unevenly distributed over space (Florida, 2005), and many cities struggle to replicate the levels of productivity and innovativeness achieved in leading regions. It is difficult for policy-makers to decide how to invest 
limited resources across the range of leading-edge technologies, especially in cities that are not at the forefront of any specific fields (Heimeriks \& Balland, 2016).

The present study addresses the question of whether it is possible to empirically specify the unique characteristics of the patent portfolios of cities in terms of technological proximity, distance, and related variety. In pursuit of this objective, we introduce a new instrument for the purpose of mapping and analysing patent portfolios of cities using data contained in patent documents issues by the Unites States Patent and Trademark Office (USPTO), which are freely available online at http://patft.uspto.gov/netahtml/PTO/ search-adv.htm, and based on routines available at https://leydesdorff.net/software/ patents/. The primary aim is to compare the specialization patterns of inventive activities in different cities.

The starting point of this analysis is the idea that the dynamics of technological knowledge are path- and place-dependent (Heimeriks \& Boschma, 2014; Kogler, 2017a), and that the current technological portfolio of a city influences the capacity to develop new technologies (Kogler et al., 2013, 2017 Kogler \& Whittle, 2018). The choice for cities as units of analysis is only one among possible applications of the suggested approach, but this focus is most relevant from the perspective of territorial innovation studies. Over the past decades investigations in the geography of innovation have produced a number of commonly accepted stylized facts (Feldman \& Kogler, 2010). Nevertheless, one can't help to observe a certain proliferation of concepts without sufficient attention to the specific operationalization, and the measurement thereof, in this line of inquiry.

We argue that the barrier between qualitative theorizing and quantitative data mining in the geography of innovation, or innovation studies more generally, can be overcome by adding statistics to the visualizations of extensive data (Breschi \& Malerba, 2001). On the one hand, the expectation is that data and statistics will provide an opportunity to test theoretically informed hypotheses regarding the technological evolution of regional economies (Boschma, Balland, \& Kogler, 2015; Boschma, Heimeriks, \& Balland, 2014; Kogler, 2017a; Kogler et al., 2013), or the diffusion of novel products and processes (Feldman, Kogler, \& Rigby, 2015). On the other hand, it is also anticipated that the proposed approach will enable analysts to formulate empirically informed hypotheses based on data-rich arguments.

Bibliographic databases such as the patents at USPTO and elsewhere, or databases of scientific publications such as at Google Scholar or the Science Citation Index, provide 'extensive' but also 'raw' data that enable us to test hypotheses more effectively than previously. However, theoretical notions have to be reformulated with reference to the measurement before one can profit from the potential in these data. These bibliometric databases provide the analyst with two main dimensions (Narin, 1976; Small \& Garfield, 1985): (i) geographical information in the address field (of authors/inventors or applicants). This address information can be aggregated and reorganized in terms of nations, regions, and cities. The second dimension (ii) reflects the intellectual organization of knowledge domains as indicated in groupings of documents on the basis of classifications. Authors, inventors, and groups of them integrate these two structural dimensions into socio-cognitive actions that one can study in the context of networks of co-authorship or co-invention.

In other words, the data enable us to differentiate between geographical, cognitive, and social maps (Rotolo, Rafols, Hopkins, \& Leydesdorff, 2017). Accordingly, concepts of 
proximity, distance, and related variety can be distinguished in these various dimensions (Frenken, Hardeman, \& Hoekman, 2009). While the geographical dimension can be overlaid onto existing maps (such as Google maps), the intellectual organization is not naturally given so that maps in this dimension have to be carefully constructed. In this study we use the map of aggregated citation relations among 630 International Patent Classes (IPC) indexed at the USPTO as a baseline for patent portfolio evaluation (Leydesdorff, Kushnir, \& Rafols, 2014). Subsequently, it will be possible to address the central research question, i.e. how are the patents developed by inventors in specific cities distributed in terms of their technological classes? We measure $(i)$ the diversity of portfolios (Rafols \& Meyer, 2010; Stirling, 2007; Zhang, Rousseau, \& Glänzel, 2016) and (ii) routines are provided to store sets of distributions as vectors in a data matrix that can be used for statistical analysis (for example, in software packages like SPSS or similar). Furthermore, (iii) input files are generated for the visualization of the portfolios as patent maps using VOSviewer (Van Eck \& Waltman, 2010).

The following section offers a brief overview of some of the relevant literature concerning the production and distribution of knowledge in space. Section 3 introduces the data and methods that will be employed in Section 4 that is dedicated to the analysis of results. The final section will provide concluding remarks, perspectives for further research in this line of inquiry, as well as policy recommendations.

\section{The knowledge production process and spatial patterns of specialization}

It has long been recognized that the accumulation of knowledge is central to economic performance (Nelson \& Winter, 1982; Romer, 1994; Schumpeter, 1943). In recent years, the importance of knowledge production has further increased due to the process of economic globalization, the ease of transmitting codified information across geographical space through the internet, globalization and outsourcing of corporate $\mathrm{R} \& \mathrm{D}$, an increase in international collaborations, and the increasing mobility of researchers (Alkemade, Heimeriks, Schoen, Villard, \& Laurens, 2015; David \& Foray, 2002; Heimeriks \& Vasileiadou, 2008).

Nevertheless, rather than observing patterns of long-term convergence in terms of the socio-economic structure of places, and in particular their technological competencies, we observe that cities have their own, unique knowledge base (Kogler et al., 2013). Cities specialize because existing skills, infrastructures and institutions facilitate the cumulative and path-dependent character of technological knowledge production (Heimeriks \& Boschma, 2014; Martin \& Sunley, 2006). The opportunities to diversify into new fields are to a large extent dependent on the existing portfolio of related technological knowledge (Boschma, Balland, \& Kogler, 2015; Kogler, Essletzbichler, \& Rigby, 2017; Rigby, 2015). New technologies evolve from the recombination of already existing building blocks of adjacent technologies (Arthur, 2007). Consequently, new technological developments are characterized by a path-dependent process of branching; new knowledge is developed from existing knowledge, skills, and infrastructures in relation to global developments (Boschma, 2017; Kogler, 2017b). From this perspective, the diversity of the technological knowledge base can be considered an important indicator of the innovative potential of a city. Portfolio analysis can help us to understand the technological capabilities and options 
of a city under study. This not only concerns potential 'smart specialization strategies' (Foray, David, \& Hall, 2009, 2011; McCann \& Ortega-Argilés, 2015; Morgan, 2015), but also potential avenues for entering new economic activities, i.e. 'smart diversification strategies' (Kogler, 2015).

Cities, and in particular large cities and metropolitan areas, have increasingly been considered as the engines of transition towards a knowledge-based economy (Florida, 2002). Because density in general spurs innovation by bringing people and ideas together and enabling them to combine and recombine in new ways, cities with their dense mixtures of people and economic activities are considered the prominent locations of innovation (Camagni, 1999; Hall, 1998; Mellander \& Florida, 2016). In other words, proximity increases the circulation not only of goods and people, but of ideas as well (Jacobs, 1969; Nomaler, Frenken, \& Heimeriks, 2014). Consequently, especially metropoles can be expected to benefit from the diversity of human and institutional resources to yield greater output in terms of technological developments, and thus they are of particular interest in the context of the present study (Bettencourt et al., 2007; Glaeser, 2011).

Over the past decades a number of concepts were introduced that focus on analysing local knowledge as a source of regional competitive advantages (Cooke \& Leydesdorff, 2006), including 'regional innovation systems' (Asheim, Isaksen, Moodysson, \& Sotarauta, 2012; Braczyk, Cooke, \& Heidenreich, 1998) and 'the learning region' (Morgan, 1997), while only recently theoretical and empirical advances in evolutionary economic geography have addressed questions regarding the rate and direction of knowledge production, and how this might translate into regional economic wealth (Boschma \& Martin, 2010; Kogler, 2017a). In this regard portfolio analysis utilizing patent data can provide insights into the specialization of countries, cities, or knowledge-producing organizations such as universities and firms (for a recent literature review, see Rafols, Porter, \& Leydesdorff, 2010; Wallace \& Rafols, 2015; Zhang, Rousseau, \& Glänzel, 2011).

Patents provide legal records of novel, nontrivial, and economic valuable ideas that help drive regional innovation and economic growth. A patent prevents an inventor's valuable idea from being commercially implemented by a business rival without penalty. Patents are essential for avoiding market failure that is likely to occur in the absence of intellectual property rights due to the positive externalities generated by novel products and processes, and knowledge in general; in essence they can be considered as vital instruments in the quest for technological development (Greenhalgh \& Rogers, 2010). On the other hand, patents are only one of many knowledge indicators and do not represent all sectors in the economy equally (Kogler, 2016).

The purpose of this paper is two-fold. First, a methodology and instrument for mapping and analysing patent portfolios is introduced. Subsequently, the theoretical objective is to understand the specialization patterns of inventive activities at the city level. From a policy perspective, portfolio analyses should inform policy makers in their mission to make best use of the existing technological strengths of cities. To the best of our knowledge, the results will for the first time provide the opportunity for the comparison of cities' individual knowledge spaces along various measures and dimensions. Furthermore, the suggested approach offers measures of technological distance that should further the understanding of the adjacent possibilities, i.e. the prospect of developing new capabilities in unoccupied knowledge domains that are adjacent to existing ones in the local knowledge space (Kogler et al., 2013). 


\section{Data and methods}

\subsection{Data}

The disadvantages of patents as overall measures of economic and inventive activity are well known (Archibugi \& Pianta, 1996; Griliches, 1990; OECD, 2009; Pavitt, 1985; Scherer, 1984). There is a strong variation in the propensity to patent among economic sectors; patenting is prevalent in what are considered high-tech or knowledge-intensive industries, e.g. information and communication technologies, chemicals, pharmaceuticals, and measuring and optical instruments (Kogler, 2016). Another limitation pertains to the skewed distribution of the value of patents (Van Zeebroeck, 2011; Van Zeebroeck \& Van Pottelsberghe de la Potterie, 2011). Notwithstanding these limitations, patents can provide important insights into the individuals and organizations actively engaged in inventive activity in technologies where the protection of intellectual property is a key aspect (Levin, Klevorick, Nelson, \& Winter, 1987).

Patent databases are widely available online (Kim \& Lee, 2015); for the present analysis the freely accessible interface of the United States Patent and Trade Office (USPTO) is utilized in order to download sets of patents in batch jobs on the basis of composed search strings. Among the various databases, USPTO data can be considered the most appropriate reflection of technological inventiveness across jurisdictions, and therefore these data have been widely applied in cross-country studies (Fu \& Yang, 2009; Johansson, Lööf, \& Savin, 2015).

We make use of the International Patent Classification (IPC) system. IPC was replaced with the Cooperative Patent Classification by USPTO and the European Patent Organization (EPO) on 1 January 2013. However, CPC classes are identical in the first four digits to IPC. ${ }^{1}$ Our routines provide four and three-digit maps, but the analysis is pursued at the four-digit level. At the four-digit level the IPC classification system contains 630 distinct technology categories, and the map is based on citation patterns among the USPTO patents grouped according to the IPC classes they are assigned to (cf. Leydesdorff, Kogler, \& Yan, 2017; Yan \& Luo, 2017).

Given the explorative nature of this research, four cities in each of five different countries were selected as examples. The objective behind this specific sample of cities is to cover sufficient variety in different dimensions. France, for example, is a larger country within the European Union with a centralized structure where Paris is the primary metropolitan area. The Netherlands on the other hand is a smaller member state where the urban hierarchy is not as pronounced. In the mix are also cities located in China, Israel, and the U.S. The five countries and selected cities are listed in Table 1.

Patents issued in 2014 were downloaded, since at the time of the retrieval (October 2015), the year 2015 was not yet complete. We use the database of granted patents (at

Table 1. Retrieval rates for four cities in five countries.

\begin{tabular}{lrlrlrlrrr}
\hline \multicolumn{2}{c}{ China } & \multicolumn{2}{c}{ France } & \multicolumn{2}{c}{ Israel } & \multicolumn{2}{c}{ Netherlands } & \multicolumn{2}{c}{ USA } \\
\hline Beijing & 2122 & Paris & 1336 & Jerusalem & 283 & Amsterdam & 253 & Boston & 874 \\
Shanghai & 1669 & Marseille & 13 & TelAviv & 876 & Rotterdam & 102 & Atlanta & 1166 \\
Nanjing & 192 & Grenoble & 422 & Haifa & 776 & Eindhoven & 884 & Berkeley & 854 \\
Dalian & 39 & Toulouse & 324 & Beersheva* & 55 & Wageningen & 43 & Boulder & 910
\end{tabular}

*The search string for Beersheva is: '(ic/Beersheva or ic/Beersheva) and icn/il and isd/2014\$\$'. 
http://patft.uspto.gov/netahtml/PTO/search-adv.htm) because this data is of higher quality than patent applications (at http://appft.uspto.gov/netahtml/PTO/search-adv. html). The application-grant lag distribution for USPTO patents shows that most patents are granted within 3 years of their application (Hall, Jaffe, \& Trajtenberg, 2001), but significant outliers remain (Popp, Juhl, \& Johnson, 2003).

The search string is as follows for non-American cities: 'ic/amsterdam and icn/nl and isd/2014\$\$'; or 'ic/boston and is/ma and isd/2014\$\$' using the state abbreviation instead of the country name for cities in the United States. The retrieval is listed in Table 1. Note that we did not limit the application dates backward.

The level of precision obtained from searching with city names is not controlled. Some cities are administratively underbounded (e.g. Amsterdam, Rotterdam) and may have suburbs that are not captured by the search while contributing to the metropolitan labour market, whereas other cities are overbounded (e.g. Boulder, CO). In the USA, Core Based Statistical Areas (CBSA) have been defined by the US Office of Management and Budget (OMB). A CBSA is a group of adjacent areas that are socioeconomically close to an urban centre. However, series of attempts at constructing a European counterpart to the metropolitan region concept of the US are still short of results, which could be used for the purpose of comparing the scientific base of large cities (Grossetti et al., 2014; Maisonobe, Eckert, Grossetti, Jégou, \& Milard, 2016).

The composition of CBSA in terms of counties can be found at http://www.uspto.gov/ web/offices/ac/ido/oeip/taf/cls_cbsa/cbsa_countyassoc.htm For the four cities in the U.S. listed in Table 1, we explore also the effects of this alternative definition. The complete search string for the CBSA 'Boston-Cambridge-Quincy, MA-NH', for example, is '(ic/ (Essex OR Middlesex OR Norfolk OR Plymouth OR Suffolk OR Boston OR Cambridge) AND IS/MA) OR (ic/(Quincy OR Rockingham OR Strafford) AND IS/NH) AND ISD/ $2014 \$ \$$ '. This search leads to a retrieval of 2265 records as against 874 patents for the original search with only 'Boston (MA)' as city name (Table 2).

\subsection{Methods}

Dedicated routines were written which enable the user to download retrieved sets in batches of 1000 patents. The routines generate files for the mapping as an overlay using VOSviewer for the visualization (Van Eck \& Waltman, 2010), and files for network analysis and visualization using Pajek (de Nooy, Mrvar, \& Batagelj, 2011). The various fields in the USPTO records are parsed and then organized in a series of databases that can be

Table 2. Search strings and retrieval for four metropolitan regions in the USA.

\begin{tabular}{lcc}
\hline City & \multicolumn{1}{c}{ Search string for the Metropolitan Area (CBSA) } & Retrieval \\
\hline Boston & (ic/(Essex OR Middlesex OR Norfolk OR Plymouth OR Suffolk OR Boston OR Cambridge) AND IS/MA) & 2265 \\
& OR (ic/(Quincy OR Rockingham OR Strafford) AND IS/NH) AND ISD/2014\$\$ & \\
Atlanta & IS/GA and isd/2014\$\$ and ic/(Atlanta OR 'Sandy Springs' OR Marietta OR Barrow OR Bartow OR Butts & 1526 \\
& OR Carroll OR Cherokee OR Clayton OR Cobb OR Coweta OR Dawson OR DeKalb OR Douglas OR & \\
& Fayette OR Forsyth OR Fulton OR Gwinnett OR Haralson OR Heard OR Henry OR Jasper OR Lamar \\
& OR Meriwether OR Newton OR Paulding OR Pickens OR Pike OR Rockdale OR Spalding OR Walton) \\
Berkeley & IS/CA and isd/2014\$\$ and ic/('San Francisco' OR Oakland OR Fremont OR Alameda OR 'Contra Costa' & 10,207 \\
& OR Marin OR 'San Mateo') & \\
Boulder & IS/CO and isd/2014\$\$ and ic/Boulder & 910 \\
\hline
\end{tabular}

*Addition of 'OR Berkeley' augments the retrieval with 534 patents to 10,741. Berkeley is part of the county Alameda in the CBSA of San Francisco-Oakland-Fremont, CA. 
related using, for example, MS Access. The procedure is further specified in Appendix I and the routines are available at http://www.leydesdorff.net/software/patents.

The routine generates additionally the files matrix.dbf and rao.dbf, which are incrementally extended with rows and columns in each subsequent run. After each retrieval, a column variable is added to the file matrix.dbf containing the distribution of the 630 CPC/IPC classes in the additional document set under study. This matrix can be read into spreadsheet and statistical software applications, e.g. Microsoft's Excel, SPSS, etc., for statistical analysis. Analogously, a row variable is added after each run to the file rao.dbf containing diversity measures (see below) as variables. As noted, these files are generated de novo if previously absent.

The routine ipc 2 cos.exe reads the file matrix.dbf and produces co-occurrence and cosinenormalized matrices which can be used for further analysis in software packages such as Pajek or UCInet (Borgatti, Everett, \& Freeman, 2002). Normalization using the cosine values (in 'cosine.net') brings the latent structure to the foreground, ${ }^{2}$ whereas visualizations based on the non-normalized file ('coocc.dat') tend to show the relational variation.

\subsection{Diversity; 'related variety'}

We are not only interested in the size of the patent portfolio of cities, but also in the diversity contained within the portfolios. Diversity may refer to both the number of different categories (e.g. technology classes) and the disparity among these categories. Rao-Stirling diversity is a measure that takes into account both the variety and the disparity in a patent portfolio under study across the IPC classes. In other words, the variety is considered as ecologically related in terms of the categories (Frenken, Van Oort, \& Verburg, 2007).

The resulting Rao-Stirling diversity is defined as follows (Rao, 1982; Stirling, 2007):

$$
\Delta=\sum_{i j} p_{i} p_{j} d_{i j}
$$

where $d_{i j}$ is a distance or disparity measure between two categories $i$ and $j$ - categories are in this case IPC classes - and $p_{i}$ is the proportion of patents assigned to each class $i$. As the disparity measure, we use $(1-$ cosine $)$ since the cosine values among all aggregated IPC is used for constructing the base map of three and four digits. Jaffe (1986) proposed the cosine between the vectors of classifications as a measure of 'technological proximity'.

Zhang et al. (2016) argues that ${ }^{2} D^{\mathrm{S}}$ provides a true diversity measure that outperforms Rao-Stirling diversity $(\Delta)$ because ${ }^{2} D^{\mathrm{S}}=2.0$ is twice as diverse as ${ }^{2} D^{\mathrm{S}}=1.0$. In their Equation 6 (at p. 1260), however, these authors formulate:

$$
{ }^{2} D^{S}=\frac{1}{(1-\Delta)}
$$

where $\Delta$ is the Rao-Stirling diversity. In other words, the transformation is monotonic and the value of ${ }^{2} D^{\mathrm{S}}$ follows directly from that of the Rao-Stirling diversity using Equation (2). This improved measure varies from zero to $\infty$ when $\Delta$ varies from zero to one. Both measures are provided for each unit of analysis in the file 'rao.dbf. Note that these are diversity measures of each portfolio in terms of the composition of IPC classes at the four digit level.

In summary, the routines enable a comparison of sets (in our case, cities) within clusters (for example, countries) or across cities and countries using multivariate analysis of the 
matrix, which is incrementally constructed during subsequent runs. This statistical analysis will be the subject of the next section; but let us first focus on an example that shows how a more descriptive approach using visualizations can provide non-obvious insights. Note that visualization is not an analytical technique. However, it allows one to recognize patterns which can then further be tested. In other words, visualizations serve the generation of hypotheses more than statistics which serve us for hypothesis testing.

\section{Results}

\subsection{Comparisons among individual cities}

Let us as a first example, zoom in on two French cities: Figure 1 shows a comparison between Paris (Figure 1(A) at the top) and Toulouse (Figure 1(B) at the bottom) overlaid on the global map of IPC. For similar illustrations of metropolitan knowledge spaces see
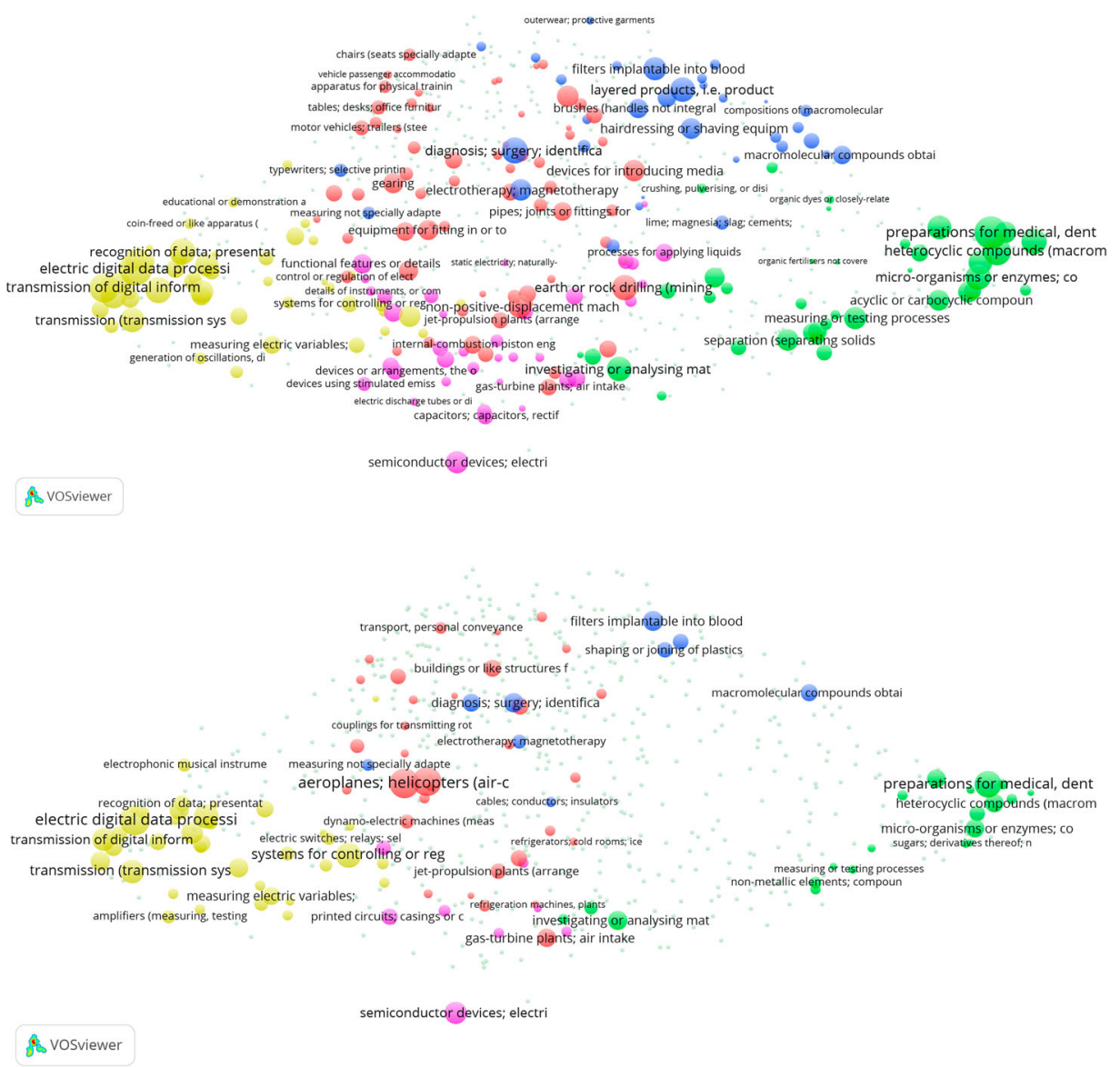

Figure 1. Overlays of patent portfolios for Paris (France) and Toulouse (France) in 2014. The map for Paris can be web-started at http://www.vosviewer.com/vosviewer.php?map=https://www.leydesdorff. net/software/patents/paris.txt\&label_size_variation=0.3\&scale=1.1; the one for Toulouse at http:// www.vosviewer.com/vosviewer.php?map=https://www.leydesdorff.net/software/patents/toulouse. txt\&label_size_variation $=0.3 \&$ scale $=1.1$ 
Kogler et al., 2013. As noted (in Table 1 above), 1336 USPTO patents were granted in 2014 to inventors with a Paris address, whereas this number was 324 for Toulouse. However, one should keep in mind that Paris is underbounded as the centre of Île-de-France, a larger metropolitan area made up of nine administrative departments (Paris, Essonne, Hauts-de-Seine, Seine-Saint-Denis, Seine-et-Marne, Val-de-Marne, Val-d'Oise, and Yvelines). ${ }^{3}$ Figure $1(\mathrm{~A})$ shows the typical pattern of patenting in a large-scale metropolitan region across the map: 226 of the 630 classes are populated. For Toulouse, a significantly smaller urban centre the number of classes occupied is just 110 .

In both figures, a cluster of bio-medical patents can be found on the right side. This cluster is found in almost all western cities and regions (Leydesdorff, Etzkowitz, \& Kushnir, 2016). In Toulouse, however, this cluster is disconnected from the largest component of 86 patent classes representing various forms of engineering and related technosciences. Figure 2 shows the network visualization of this component (extracted from the set). In this local representation - no longer projected onto the global map of 630 categories - the airplane industry, which is of significant size in Toulouse due to the presence of Airbus, is visible in a cluster of patents at the bottom-right, but is somewhat distant from the other technology clusters in the city.

In Table 3, the patent portfolios of Paris and Toulouse are compared as local networks of co-occurring classifications. ${ }^{4}$ Values for Toulouse are lower than for Paris in most cases; but centralization is higher for Toulouse than Paris. The density of the network of Toulouse is almost twice as high when compared with Paris. In other words, the clustering of technological knowledge as indicated by the classification codes found in patents generated by inventors residing in Toulouse is more concentrated when compared with Paris where patents are more diverse and spread across the spectrum of IPC classes.

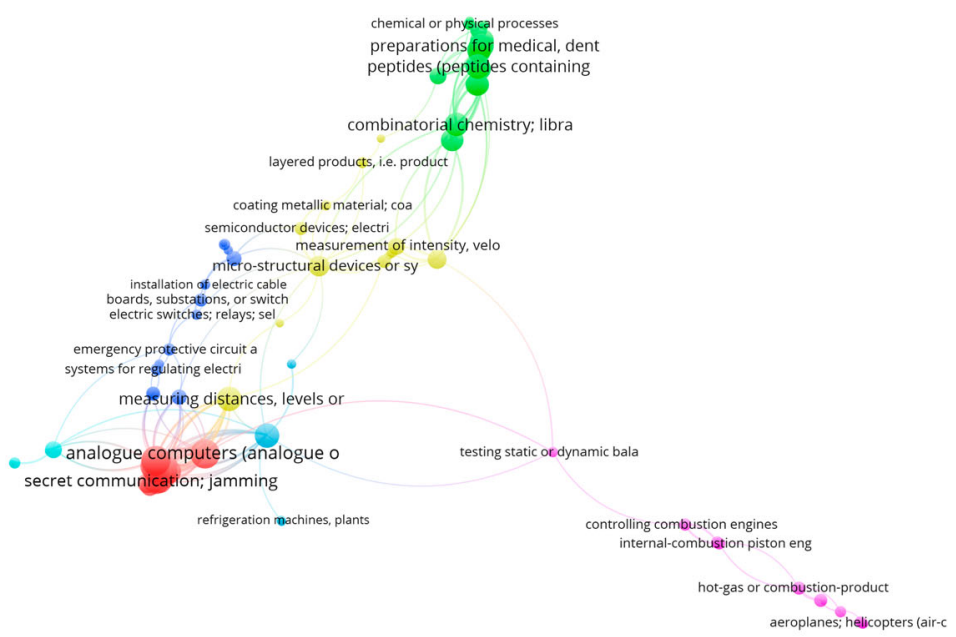

B vosviewer

Figure 2. Largest component of 86 (among 110) patent classes with an inventor address in Toulouse, France. The map can be web-started at http://www.vosviewer.com/vosviewer.php?map=https://www. leydesdorff.net/software/patents/toul86.txt\&network=https:/www.leydesdorff.net/software/patents/ toul86n.txt\&label_size_variation $=0.3 \&$ scale $=1.25 \&$ colored_lines\&curved_lines\&n_lines=10000; threshold: cosine $>0.2$. 
Table 3. Network cohesion measures of the portfolios of Paris and Toulouse (using UCInet).

\begin{tabular}{llcc}
\hline UCInet & Network cohesion measures & Paris & Toulouse \\
\hline 1 & Avg Degree & 8.159 & 6.855 \\
2 & Indeg H-Index & 24 & 16 \\
3 & Deg Centralization & 0.138 & 0.17 \\
4 & Out-Central & 0.138 & 0.168 \\
5 & In-Central & 0.138 & 0.168 \\
6 & Density & 0.036 & 0.063 \\
7 & Components & 25 & 16 \\
8 & Component Ratio & 0.107 & 0.138 \\
9 & Connectedness & 0.744 & 0.613 \\
10 & Fragmentation & 0.256 & 0.387 \\
11 & Closure & 0.666 & 0.748 \\
12 & Avg Distance & 4.184 & 4.032 \\
13 & SD Distance & 1.761 & 2.098 \\
14 & Diameter & 12 & 11 \\
15 & Breadth & 0.775 & 0.786 \\
16 & Compactness & 0.225 & 0.214 \\
\hline
\end{tabular}

In summary, the analysis of the networks in Paris and Toulouse shows a clear distinction between a large metropole with a diverse technological knowledge base and a more specialized medium-sized city. From a policy perspective, this raises the issue about what strategies are available for these two locations pending further reflections.

For Toulouse, an obvious strategy seems to be to identify options for related diversification (Boschma, 2017; Kogler, 2017b). Given its strong pattern of specialization, adjacent technological opportunities can be identified. For Paris, its advantage lies in the diversity of its technological knowledge base. In addition to expanding its many technological strengths through related diversification, Paris seems well positioned to further develop a comparative advantage in complex technological knowledge that requires a recombination of diverse technological building blocks at both the global and local levels (Fleming \& Sorenson, 2001).

\subsection{Statistical analysis at the level of the set}

In addition to network analysis of co-classifications, the routine enables us to compare portfolios by considering patent classes as attributes to the cities. To this end a matrix is incrementally constructed: in each run a variable is added. This variable has values larger than zero for the classes which are attributed. For example, in the case of Paris 226 classes are used, and (630-226 =) 404 classes are empty. Unlike in the previous analysis where the focus has been on the relations among patent classes, this matrix enables one to analyse correlations between portfolios of cities. In contrast to the relational (network) analysis, correlations span a vector-space in which one can distinguish densities or principal components.

The matrix of 630 IPC classes versus 20 (five times four) cities can be used as input for multi-variate analysis in a statistics programme such as SPSS. The portfolios of Paris and Toulouse are correlated with Pearson $r=.691(p<.01)$; the Spearman rank-order correlation $\rho=.472(p<.01)$. The lower value of the rank-order correlation indicates that the portfolios have different foci more than suggested by the visuals. Note that the correlation is partially caused by the large number of zeros. The rank-order correlation for the 83 
classes attributed to both cities is .620 $(p<.01)$; the cosine, a non-parametric equivalent of the Pearson correlation (Ahlgren, Jarneving, \& Rousseau, 2003), is 0.703.

Table 4 shows the result of discriminant analysis using the portfolios of cities as predictors of the national origins. Since the latter is known ex ante, one can note that the statistical prediction is perfect $(100 \%)$ for the USA and China. France, Israel and the Netherlands each contain one city with a profile that is sorted by the routine into the Chinese group. These are respectively: Marseille, Beersheva, and Wageningen. Consequently, the discrimination is not statistically significant; the Dutch cities, notably, entertain portfolios which are close to the ones of China (Figure 3). Nevertheless, a national character of the portfolios is weakly indicated. The USA is the outlier in Figure 3, but this may be a consequence of using USPTO data.

Table 5 shows the results of factor analysis of the 20 cities as variables. ${ }^{5}$ Three factors explain $78.3 \%$ of the variance. Factor 1 assembles the cities with a portfolio focusing on engineering; factor 2 indicates a prevailing portfolio in the bio-medical domain, whereas only Dalian (China) and Amsterdam (Netherlands) score highest on factor 3. This latter factor is more difficult to designate.

While Beijing has the highest loading on factor 1, Dalian has a very different pattern of patenting. In order to further understand the difference between these two cities, one could, for example, map Dalian versus Beijing analogously as we mapped Toulouse versus Paris in Figure 1. The factor analysis thus suggests a way forward if one is particularly interested in Chinese portfolios, or in evaluating differences amongst places altogether.

\subsection{A map of the 20 cities}

The matrix of 20 cities versus 630 patent classes enables us also to make a distance matrix using for example the cosine values between the vectors. The cosine is a similarity measure, but $(1-$ cosine $)$ provides us with a dissimilarity measure or distance. Feeding these distances into a visualization programme one can map and cluster the cities. In other words, these distributions are normalized. By adding geo-codes to the cities, one would also able to map the cities geographically (Leydesdorff \& Bornmann, 2012).

Using VOSviewer for the clustering and the mapping, two types of portfolios are distinguished, as indicated with green and red in Figure 4. The divide can be characterized as

Table 4. Discriminant analysis of 20 cities in terms of 630 patent classes.

\begin{tabular}{|c|c|c|c|c|c|c|c|c|}
\hline \multicolumn{9}{|c|}{ Classification results $^{\mathrm{a}}$} \\
\hline & & & \multicolumn{5}{|c|}{ Predicted group membership } & \multirow[b]{2}{*}{ Total } \\
\hline & \multicolumn{2}{|c|}{ Country } & France & Israel & China & USA & Nether-lands & \\
\hline \multirow[t]{10}{*}{ Original } & \multirow[t]{5}{*}{ Count } & France & 3 & 0 & 1 & 0 & 0 & 4 \\
\hline & & Israel & 0 & 3 & 1 & 0 & 0 & 4 \\
\hline & & China & 0 & 0 & 4 & 0 & 0 & 4 \\
\hline & & USA & 0 & 0 & 0 & 4 & 0 & 4 \\
\hline & & Netherlands & 0 & 0 & 1 & 0 & 3 & 4 \\
\hline & \multirow[t]{5}{*}{$\%$} & France & 75.0 & 0.0 & 25.0 & 0.0 & 0.0 & 100.0 \\
\hline & & Israel & 0.0 & 75.0 & 25.0 & 0.0 & 0.0 & 100.0 \\
\hline & & China & 0.0 & 0.0 & 100.0 & 0.0 & 0.0 & 100.0 \\
\hline & & USA & 0.0 & 0.0 & 0.0 & 100.0 & 0.0 & 100.0 \\
\hline & & Netherlands & 0.0 & 0.0 & 25.0 & 0.0 & 75.0 & 100.0 \\
\hline
\end{tabular}

a $85.0 \%$ of original grouped cases correctly classified. 


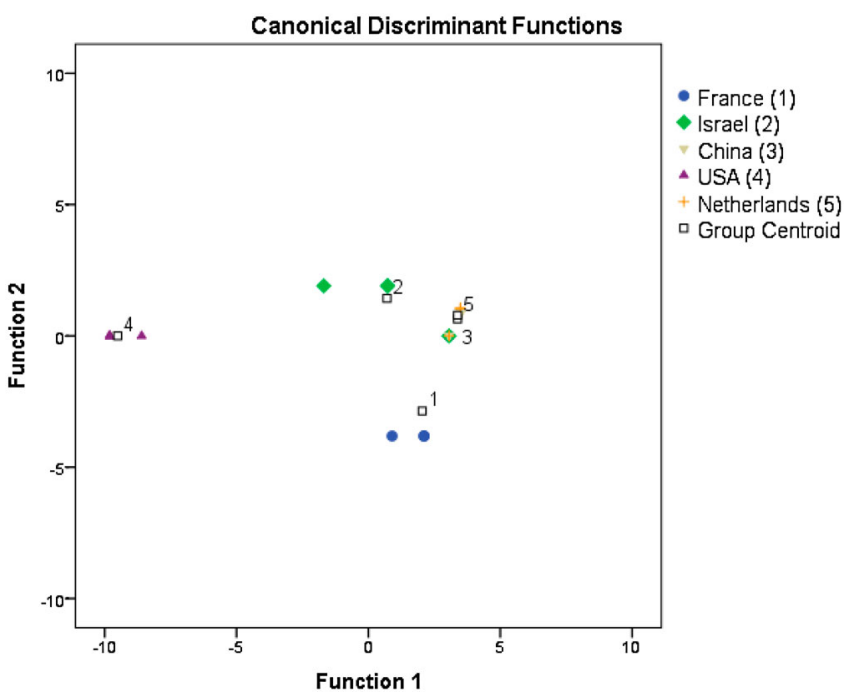

Figure 3. All-groups scatterplot of the twenty cities in four countries using canonical discriminant functions.

American-Pacific versus American-Atlantic portfolios. Leydesdorff, Etzkowitz, et al. (2016) found a similar divide when analysing university patents at the level of countries. An alternative characterization, however, in terms of engineering versus bio-medicine explains also why Toulouse, Grenoble, and Eindhoven are part of the red-coloured cluster. The factor-analysis (Table 5) informs us that these cities are weakly loading on the relevant factor 1 . In this two-cluster solution, Dalian resides in the vicinity of

Table 5. Varimax-rotated factor matrix of the patent portfolios of 20 cities.

\begin{tabular}{|c|c|c|c|}
\hline & \multicolumn{3}{|c|}{ Component } \\
\hline & 1 & 2 & 3 \\
\hline Beijing & .923 & .174 & .107 \\
\hline Haifa & .902 & .291 & \\
\hline Berkeley & .884 & .340 & \\
\hline Tel Aviv & .876 & .377 & \\
\hline Atlanta & .858 & .369 & \\
\hline Boulder & .818 & .382 & \\
\hline Shanghai & .802 & .358 & .218 \\
\hline Nanjing & .737 & .370 & .271 \\
\hline Grenoble & .729 & & .135 \\
\hline Toulouse & .662 & .454 & \\
\hline Eindhoven & .613 & & \\
\hline Marseille & .521 & .500 & .170 \\
\hline Wageningen & & .816 & \\
\hline Boston & .456 & .811 & .176 \\
\hline Paris & .471 & .810 & .150 \\
\hline Rotterdam & .223 & .799 & \\
\hline Beersheva & .451 & .779 & \\
\hline Jerusalem & .611 & .731 & \\
\hline Dalian & & & .951 \\
\hline Amsterdam & .244 & .622 & .634 \\
\hline
\end{tabular}

Extraction Method: Principal Component Analysis.

Rotation Method: Varimax with Kaiser Normalization. a. Rotation converged in 5 iterations. 
Amsterdam and Marseille in the Atlantic cluster. Note that these two European cities showed interfactorial complexity.

\subsection{Related variety}

In Table 6, we rank the 20 cities in terms of decreasing Rao-Stirling diversity, and compare this with the portfolio analysis of these 20 cities using scientific publications in the Web of Science provided in a previous study (Leydesdorff, Heimeriks, \& Rotolo, 2016). As explained in the methods section, Rao-Stirling diversity can be considered as a measure of 'related variety' (Castaldi, Frenken, \& Los, 2015; Frenken et al., 2007). The measure is also called 'quadratic entropy' or 'ecological entropy' (Izsák \& Papp, 1995; Rao, 1982; Ricotta \& Szeidl, 2006). The ecological distance $\left(d_{i j}\right)$ between species $i$ and $j$ is multiplied by their variety $\left(p_{i}{ }^{\star} p_{j}\right){ }^{6}$ Variety which is 'related' - such as in an ecological niche - is thus accounted for differently from variety which is 'unrelated'. Unlike Castaldi et al. (2015), this formulation does not require the definition of given categories, such as nested levels of the IPC, but only a distance measure such as (1 - cosine) (Jaffe, 1989).

We use $\left(1-\operatorname{cosine}_{i j}\right)$ as a measure of dissimilarity or distance in this case; the cosine is provided between each two of the 630 IPC4 classes in a file at http://www.leydesdorff.net/ ipcmaps/cos_ipc4.dbf In Table 6, the resulting values are listed in rank order. In the right half of the table, the values of $\Delta$ are provided from a previous study in which portfolios of journals were analyzed for the same 20 cities (Leydesdorff, Heimeriks, et al., 2016, Table 3, p. 746).

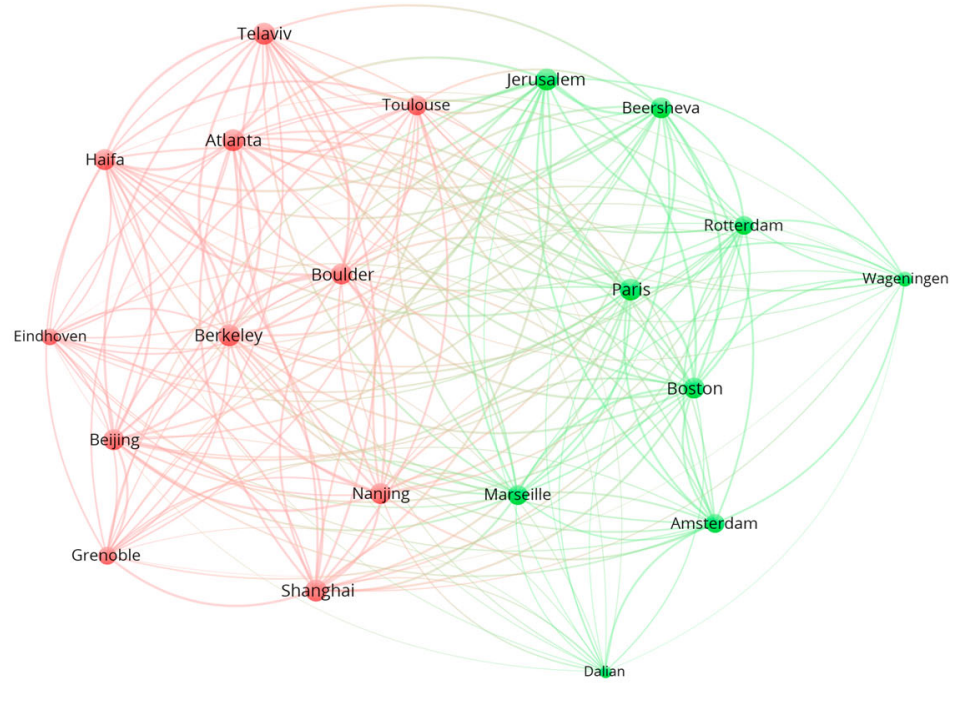

\& Vosviewer

Figure 4. Cosine-normalized network among 20 cities; VOSviewer is used for the mapping and clustering. The map can be web-started at http://www.vosviewer.com/vosviewer.php?map=https://www. leydesdorff.net/software/patents/cos_map.txt\&network=https://www.leydesdorff.net/software/ patents/cos_net.txt\&label_size_variation $=0.3 \&$ scale $=1.40 \&$ colored_lines\&curved_lines\&n_lines $=$ 10000\&line_size_variation $=0.55$. 
Table 6. Rao-Stirling diversity for 20 cities in USPTO and WoS, respectively.

\begin{tabular}{lcrlcc}
\hline USPTO $(\mathrm{a})$ & Rao $\Delta(\mathrm{b})$ & $\mathrm{N}(\mathrm{c})$ & WoS $(\mathrm{d})$ & Rao $\Delta(\mathrm{e})$ & $\mathrm{N}(\mathrm{f})$ \\
\hline SHANGHAI & 0.8894 & 1669 & Haifa & 0.3277 & 3408 \\
EINDHOVEN & 0.8725 & 884 & Beersheva & 0.3138 & 1905 \\
PARIS & 0.8702 & 1336 & Tel Aviv & 0.3128 & 4206 \\
ROTTERDAM & 102 & Paris & 0.3112 & 24,877 \\
DALIAN & 0.8684 & 39 & Marseille & 0.3081 & 5293 \\
BOULDER & 0.8653 & 910 & Toulouse & 0.3043 & 5899 \\
TOULOUSE & 0.8637 & 324 & Jerusalem & 0.2981 & 3414 \\
AMSTERDAM & 0.8630 & 253 & Shanghai & 0.2915 & 29,166 \\
NANJING & 0.8557 & 192 & Atlanta & 0.2846 & 14,296 \\
GRENOBLE & 0.8532 & 422 & Eindhoven & 0.2838 & 2554 \\
BEERSHEVA & 0.8510 & 55 & Amsterdam & 0.2737 & 13,451 \\
BOSTON & 0.8458 & 874 & Berkeley & 0.2719 & 8868 \\
ATLANTA & 0.8447 & Beijing & 0.2621 & 58,032 \\
BERKELEY & 0.8446 & Nanjing & 0.2547 & 17,713 \\
JERUSALEM & 0.8215 & Grenoble & 0.2457 & 5564 \\
BEIJING & 0.8116 & 283 & Boulder & 0.2216 & 5274 \\
TEL AVIV & 0.8047 & 8122 & Boston & 0.2091 & 31,182 \\
HAIFA & 0.7748 & 776 & Wageningen & 0.2010 & 3178 \\
MARSEILLE & 0.7578 & 13 & Dalian & 0.2004 & 5023 \\
WAGENINGEN & 0.7061 & 43 & Rotterdam & 0.1932 & 5721 \\
\hline
\end{tabular}

The numbers of patents and publications ( $N$ in Table 6$)$ are significantly correlated $(r$ $=0.753 ; p<0.01)$. However, this correlation may be spurious: both numbers can be expected to co-vary with size. The diversity, however, is negatively correlated $(r=$ $-0.102 ; n . s$.). In other words, patenting and publishing operate in two different selection environments. ${ }^{7}$

For example, the Israeli cities Haifa, Beersheva, and Tel Aviv were ranked as the highest on diversity in terms of journal publications (in WoS), but Haifa and Tel Aviv are among the lowest in terms of diversity among the patents. In other words, these cities contain knowledge-producing institutions (e.g. universities) which are prolific and publish in a large number of fields. However, their patenting portfolios are specific. The selection mechanisms for patents are very different from those for publications.

\subsection{Cities and metropolitan areas}

In the following, we added the retrieval for the CBSA 14460, entitled 'Boston-CambridgeQuincy, MA-NH', to the retrieval for 'Boston, MA' as a separate variable. Figure 5 shows the effect of this addition to the same set as used for Figure 4. As can be expected, the larger region is more central than the city. However, the figures are virtually identical. Correlations between the two portfolios (Boston as a city and as CBSA) as distributions of patents over patent classes are large and highly significant: Pearson's $r=.984(p<0.01)$; Spearman's $\rho=.835(p<0.01)$; cosine $=0.984$. The factor analysis using Boston CBSA instead of the city is virtually the same (Table 7; cf. Table 5). The number of patents in the CBSA is almost three times larger than that for the city itself (Table 2 above).

Three factors explain $78.5 \%$ of the variance (vs. $78.3 \%$ in Table 5 above). In summary, the structure of the matrix is not different; the vector for the city of Boston is structurally similar to that of the CBSA of Boston, whereas the $N$ of granted patents is almost three times larger. 


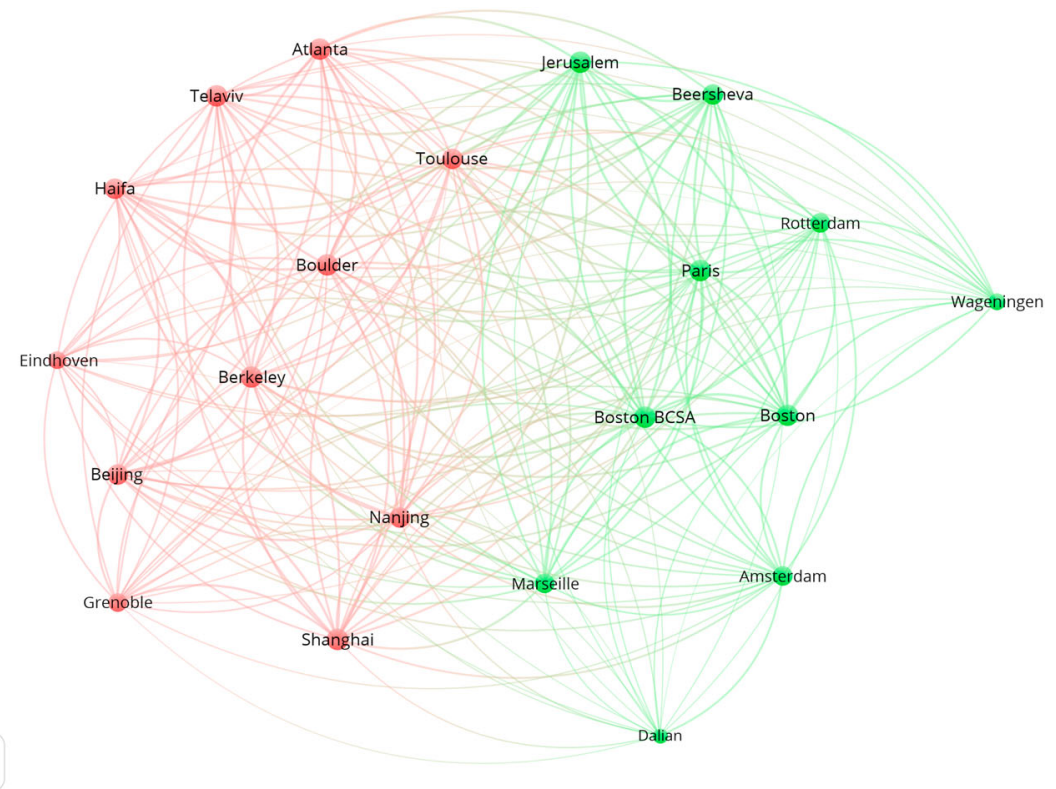

Figure 5. Cosine-normalized network among 20 cities and the CBSA of Boston ; VOSviewer is used for the clustering and mapping. The map can be web-started at http://www.vosviewer.com/vosviewer. php?map=https://www.leydesdorff.net/software/patents/cos_map2.txt\&network=https://www. leydesdorff.net/software/patents/cos_net2.txt\&label_size_variation $=0.3 \&$ scale $=1.40 \&$ colored_ lines\&curved_lines\&n_lines=1000\&line_size_variation=0.55.

Table 7. Varimax-rotated factor matrix of the patent portfolios of the same 19 cities and the 'CBSA Boston-Cambridge-Quincy, MA-NH' instead of 'Boston, MA' as a single city address.

\begin{tabular}{|c|c|c|c|}
\hline \multicolumn{4}{|c|}{ Rotated Component Matrix } \\
\hline & \multicolumn{3}{|c|}{ Component } \\
\hline & 1 & 2 & 3 \\
\hline Beijing & .921 & .177 & .107 \\
\hline Haifa & .903 & .286 & \\
\hline Berkeley & .885 & .336 & \\
\hline Tel-Aviv & .877 & .374 & \\
\hline Atlanta & .860 & .362 & \\
\hline Boulder & .822 & .372 & \\
\hline Shanghai & .802 & .360 & .217 \\
\hline Nanjing & .737 & .369 & .273 \\
\hline Grenoble & .727 & & .132 \\
\hline Toulouse & .662 & .456 & \\
\hline Eindhoven & .612 & & \\
\hline Marseille & .525 & .495 & .171 \\
\hline Wageningen & & .823 & \\
\hline Paris & .474 & .807 & .152 \\
\hline Rotterdam & .223 & .802 & \\
\hline CBSA Boston & .544 & .776 & .170 \\
\hline Beersheva & .455 & .774 & \\
\hline Jerusalem & .614 & .727 & \\
\hline Dalian & & & \\
\hline Amsterdam & .243 & .622 & .636 \\
\hline
\end{tabular}

Extraction Method: Principal Component Analysis. Rotation Method: Varimax with Kaiser Normalization. ${ }^{\mathrm{a}}$ Rotation converged in 5 iterations. 


\section{Discussion and concluding remarks}

A number of recent studies have employed patent data, in particular patent classifications, for the development of metropolitan and regional knowledge spaces (Kogler et al., 2013; 2017; Rigby, 2015). The primary focus in these inquiries is on the evolution of regional knowledge spaces, while the analysis is based on measures derived from cooccurrence matrices of IPC codes. In the present study, a similar approach has been followed. The aim was to empirically specify the characteristics of patent portfolios of cities in terms of technological proximity, distance, and related variety. For this purpose, we first developed a new instrument for the mapping and analysis of patent portfolios of cities. Secondly, an analytical framework was developed that allows for the statistical comparison of knowledge space properties amongst entities - in this case cities. This further step is highly relevant from a policy perspective: the prospect of capturing, analysing, and comparing the technological knowledge competencies of a specific city vis-à-vis other places provides the opportunity for policy-makers and other stakeholders to identify the most promising avenues for deepening the local knowledge base as well as where to invest limited resources, for further technological upgrading (Heimeriks \& Balland, 2016). The present approach provides important insights to the Smart Specialization Strategies framework (Foray, 2015) that highlights to the importance of relative strengths and capabilities present in a given locality as a starting point for the development of more effective development pathways (Kogler \& Whittle, 2018).

The examples outlined above demonstrate that cities have different technological portfolios. Given this variation, a 'one size fits all' policy at the national level to further develop the technological knowledge base of cities can be counterproductive. Although the results provide the opportunity for comparing peer cities, this information needs to be supplemented with contextual information. This includes the cities' particular strategies and missions, qualitative information regarding the institutional similarities between the cities in question, the relative location, but also the relative position in the hierarchy of technological advancement. In this way, the suggested approach can be used as a tool to benchmark a city in comparison to relevant peers, which in turn may help to identify relevant best-practices in well-performing cities that are otherwise comparable in terms of their knowledge base and specialization patterns.

The results of the discriminant analysis indicated that national institutional settings are an aspect of understanding the patent portfolio of cities. Frequently urban centres belonging to the same country also display similar positions in the knowledge space. This is in line with previous theoretical and qualitative case study insights emanating from the national innovation systems literature (Lundvall, 1988; Nelson, 1993). However, these results also connect to the arguments in the relevant literature that states that development outcomes are place-specific due to the mainly path-dependent trajectories inherent to the process of technological change (Kogler, 2017a; Martin \& Sunley, 2006). In summary, patent portfolios of cities can be expected to be both geographically tainted and historically specific. Our methods may be less appropriate for the specification of disruptive forms of technological renewal that may, among other things, lead to lock-in into patterns of technological decline. 
The idea that cities within the same national jurisdiction, i.e. the same national ecosystem of innovation, are predominantly located in close vicinity in the knowledge space points to a degree of national rather than just place-specific path-dependency. This in turn links back to the instance that countries frequently pursue a common national science- and technology-policy approach that is then generically applied in a top-down fashion to all localities within the territory, while in reality place-based specific policies would require a bottom-up approach that takes into consideration the knowledge competencies that already exist, which consecutively would allow for identifying the most promising future local development pathways. From this perspective, measures of technological distance create an understanding of the adjacent possibilities for further knowledge production that is available for diversification (Boschma, 2017; Kogler, 2017b). Further, the proposed approach and subsequent analysis presented above also outlines how relatedness measures, based on the presence and connectedness of technology domains in a given place, can be used to operationalize effective Smart Specialization Strategies based on empirical evidence, something that is frequently missing in such actions (Kogler \& Whittle, 2018).

\section{Notes}

1. CPC contains new categories classified under ' $Y$ ' that span different sections of the IPC in order to indicate new technological developments (Scheu et al., 2006; Veefkind, HurtadoAlbir, Angelucci, Karachalios, \& Thumm, 2012).

2. The cosine is similar to the Pearson correlation except that the distributions are not $z$-normalized to the mean. Since the patent distributions are non-normal (but skewed), this measure is more appropriate (Ahlgren et al., 2003).

3. Because of the diacritical characters searching with these names is difficult in the USPTO search interface; we found one patent with 'Essone' in the address field, three with 'Valde-Marne', and seven with 'Yvelines', granted in 2014.

4. UCInet enables the user to generate these network statistics in a single pass.

5. We use the transposed matrix because factor scores are more difficult to read, while factor scores do not vary between -1 and +1 .

6. $\left(p_{\mathrm{i}}{ }^{*} p_{\mathrm{j}}\right)$ is the Gini-Simpson index. The Gini-Simpson is equal to the complement to one of the Herfindahl-Hirsch index or equivalently the Simpson index (Stirling, 2007).

7. We use Zhang et al.'s (2016) diversity measure $\left({ }^{2} D^{5}\right)$ for estimating this correlation since ${ }^{2} D^{S}=1 / 1-\Delta$ measures 'true diversity' with which one is allowed to calculate as a variable at the ratio scale.

\section{Acknowledgments}

The authors would like to thank two anonymous referees for comments on an earlier draft. The usual disclaimer applies.

\section{Disclosure statement}

No potential conflict of interest was reported by the authors.

\section{Funding}

Dieter F. Kogler would like to acknowledge funding from the European Research Council under the European Union's Horizon 2020 research and innovation programme (grant agreement No 715631, TechEvo). 


\section{ORCID}

Dieter Franz Kogler (D) http://orcid.org/0000-0002-6744-5632

Gaston Heimeriks (i) http://orcid.org/0000-0002-0577-6938

Loet Leydesdorff (iD http://orcid.org/0000-0002-7835-3098

\section{References}

Ahlgren, P., Jarneving, B., \& Rousseau, R. (2003). Requirements for a cocitation similarity measure, with special reference to Pearson's correlation coefficient. Journal of the American Society for Information Science and Technology, 54(6), 550-560. doi:10.1002/asi.10242

Alkemade, F., Heimeriks, G., Schoen, A., Villard, L., \& Laurens, P. (2015). Tracking the internationalization of multinational corporate inventive activity: National and sectoral characteristics. Research Policy, 44(9), 1763-1772. doi:10.1016/j.respol.2015.01.007

Archibugi, D., \& Pianta, M. (1996). Measuring technological change through patents and innovation surveys. Technovation, 16(9), 451-468.

Arthur, B. (2007). The structure of invention. Research Policy, 36, 274-287. doi:10.1016/j.respol. 2006.11.005

Asheim, B., Isaksen, A., Moodysson, J., \& Sotarauta, M. (2012). Knowledge bases, modes of innovation and regional innovation policy. In H. Bathelt, M. Feldman, \& D. F. Kogler (Eds.), Beyond territory: Dynamic geographies of knowledge creation, diffusion, and innovation (pp. 227-249). London: Routledge.

Bairoch, P. (1988). Cities and economic development: From the Dawn of history to the present. Chicago: University Press, Chicago.

Bettencourt, L. M. A., Lobo, J., Helbing, D., Kühnert, C., \& West, G. B. (2007). Growth, innovation, scaling, and the pace of life in cities. Proceedings of the National Academy of Sciences of the United States of America, 104(17), 7301-7306. doi:10.1073/pnas.0610172104

Borgatti, S. P., Everett, M. G., \& Freeman, L. C. (2002). Ucinet for windows: Software for social network analysis. Harvard: Analytic Technologies.

Boschma, R. (2017). Relatedness as driver of regional diversification: A research agenda. Regional Studies, 51(3), 351-364. doi:10.1080/00343404.2016.1254767

Boschma, R., Balland, P.-A., \& Kogler, D. F. (2015). Relatedness and technological change in cities: The rise and fall of technological knowledge in US metropolitan areas from 1981 to 2010. Industrial and Corporate Change, 24, 223-250. doi:10.1093/icc/dtu012

Boschma, R., Heimeriks, G., \& Balland, P.-A. (2014). Scientific knowledge dynamics and relatedness in biotech cities. Research Policy, 43(1), 107-114. doi:10.1016/j.respol.2013.07.009

Boschma, R., \& Martin, R. (2010). The aims and scope of evolutionary economic geography. In R. Boschma \& R. Martin (Eds.), The handbook of evolutionary economic geography (pp. 3-39). Cheltenham: Edward Elgar.

Braczyk, H.-J., Cooke, P., \& Heidenreich, M. (Eds.). (1998). Regional innovation systems: The role of governances in a globalized world. London: UCL Press.

Breschi, S., \& Malerba, F. (2001). The geography of innovation and economic clustering: Some introductory notes. Industrial and Corporate Change, 10, 817-833. doi:10.1093/icc/10.4.817

Camagni, R. (1999). The city as a Milieu: Applying the Gremi approach to urban evolution. Révue d'Economie Régionale et Urbaine, 3, 591-606.

Carlino, G. A., Chatterjee, S., \& Hunt, R. M. (2007). Urban density and the rate of invention. Journal of Urban Economics, 61, 389-419. doi:10.1016/j.jue.2006.08.003

Castaldi, C., Frenken, K., \& Los, B. (2015). Related variety, unrelated variety and technological breakthroughs: An analysis of US state-level patenting. Regional Studies, 49(5), 767-781. doi:10.1080/00343404.2014.940305

Cooke, P., \& Leydesdorff, L. (2006). Regional development in the knowledge-based economy: The construction of advantage. The Journal of Technology Transfer, 31, 5-15. doi:10.1007/s10961005-5009-3 
David, P. A., \& Foray, D. (2002). An introduction to the economy of the knowledge society. International Social Science Journal, 54(171), 9-23. doi:10.1111/1468-2451.00355

de Nooy, W., Mrvar, A., \& Batagelj, V. (2011). Exploratory social network analysis with Pajek. Cambridge: Cambridge University Press.

Feldman, M. P., \& Kogler, D. F. (2010). Stylized facts in the geography of innovation. In B. Hall \& N. Rosenberg (Eds.), Handbook of the economics of innovation (pp. 381-410). Oxford: Elsevier.

Feldman, M. P., Kogler, D. F., \& Rigby, D. L. (2015). Rknowledge: The spatial diffusion and adoption of rDNA methods. Regional Studies, 49(5), 798-817. doi:10.1080/00343404.2014.980799

Fleming, L., \& Sorenson, O. (2001). Technology as a complex adaptive system: Evidence from patent data. Research Policy, 30(7), 1019-1039. doi:10.1016/S0048-7333(00)00135-9

Florida, R. (2002). The rise of the creative class. And how it's transforming work, leisure and everyday life. New York: Basic Books.

Florida, R. (2005). The world is spiky. The Atlantic monthly. Retrieved from https://www. theatlantic.com/past/docs/images/issues/200510/world-is-spiky.pdf

Foray, D. (2015). Smart specialization: Opportunities and challenges for regional innovation policy. Abingdon: Routledge.

Foray, D., David, P., \& Hall, B. (2009, June). Smart specialization - the concept. Knowledge Economists Policy Brief Number 9, European Commission, Brussels: DG Research.

Foray, D., David, P. A., \& Hall, B. H. (2011). Smart specialization. From academic idea to political instrument, the surprising career of a concept and the difficulties involved in its implementation. MTEI Working Paper.

Frenken, K., Hardeman, S., \& Hoekman, J. (2009). Spatial scientometrics: Towards a cumulative research program. Journal of Informetrics, 3(3), 222-232. doi:10.1016/j.joi.2009.03.005

Frenken, K., Van Oort, F., \& Verburg, T. (2007). Related variety, unrelated variety and regional economic growth. Regional Studies, 41(5), 685-697. doi:10.1080/00343400601120296

Fu, X., \& Yang, Q. G. (2009). Exploring the cross-country gap in patenting: A stochastic frontier approach. Research Policy, 38, 1203-1213. doi:10.1016/j.respol.2009.05.005

Glaeser, E. (2011). Cities: Engines of innovation. Scientific American, 305, 50-55. doi:10.1038/ scientificamerican0911-50

Greenhalgh, C., \& Rogers, M. (2010). Innovation, intellectual property, and economic growth. Princeton, NJ: Princeton University Press.

Griliches, Z. (1990). Patent statistics as economic indicators: A survey. Journal of Economic Literature, 28, 1661-1707.

Grossetti, M., Eckert, D., Gingras, Y., Jégou, L., Larivière, V., \& Milard, B. (2014). Cities and the geographical deconcentration of scientific activity: A multilevel analysis of publications (19872007). Urban Studies, 51(10), 2219-2234. doi:10.1177/0042098013506047

Hall, B. H., Jaffe, A. B., \& Trajtenberg, M. (2001). The NBER patent citations data file: Lessons, insights and methodological tools (NBER Working Paper No. 8498), pp. 1-46.

Hall, P. (1998). Cities in civilization: Culture, technology, and urban order. New York: Pantheon Books.

Heimeriks, G., \& Balland, P. A. (2016). How smart is specialisation? An analysis of specialisation patterns in knowledge production. Science and Public Policy, 43(4), 562-574. doi:10.1093/ scipol/scv061

Heimeriks, G., \& Boschma, R. (2014). The path- and place-dependent nature of scientific knowledge production in biotech 1986-2008. Journal of Economic Geography, 14(2), 339-364. doi: $10.1093 /$ jeg/lbs052

Heimeriks, G., \& Vasileiadou, E. (2008). Changes or transition? Analysing the use of ICTs in the sciences. Social Science Information, 47(1), 5-29. doi:10.1177/0539018407085747

Izsák, J., \& Papp, L. (1995). Application of the quadratic entropy indices for diversity studies of drosophilid assemblages. Environmental and Ecological Statistics, 2(3), 213-224. doi:10.1007/ BF00456668

Jacobs, J. M. (1969). The economy of cities. New York: Random House.

Jaffe, A. B. (1986). Technological opportunity and spillovers of R\&D: Evidence from firm's patents, profits, and market value. American Economic Review, 76(5), 984-1001. 
Jaffe, A. B. (1989). Characterizing the "technological position" of firms, with application to quantifying technological opportunity and research spillovers. Research Policy, 18(2), 87-97. doi:10. 1016/0048-7333(89)90007-3

Johansson, B., Lööf, H., \& Savin, M. (2015). European R\&D efficiency. Economics of Innovation and New Technology, 24(1-2), 140-158. doi:10.1080/10438599.2014.897857

Kim, J., \& Lee, S. (2015). Patent databases for innovation studies: A comparative analysis of USPTO, EPO, JPO and KIPO. Technological Forecasting and Social Change, 92, 332-345. doi:10.1016/j. techfore.2015.01.009

Kogler, D. F. (2015). Editorial: Evolutionary economic geography - theoretical and empirical progress. Regional Studies, 49(5), 705-711. doi:10.1080/00343404.2015.1033178

Kogler, D. F. (2016). Intellectual property and patents in manufacturing industries. In J. Bryson, J. Clark, \& V. Vanchan (Eds.), The handbook of manufacturing industries in the world economy (pp. 163-188). Northampton: Edward Elgar.

Kogler, D. F. (Ed.). (2017a). Evolutionary economic geography: Theoretical and empirical progress. London: Routledge.

Kogler, D. F. (2017b). Relatedness as driver of regional diversification: A research agenda - A commentary. Regional Studies, 51(3), 365-369. doi:10.1080/00343404.2016.1276282

Kogler, D. F., Essletzbichler, J., \& Rigby, D. L. (2017). The evolution of specialization in the EU15 knowledge space. Journal of Economic Geography, 17(2), 345-373. doi:10.1093/jeg/lbw024

Kogler, D. F., Rigby, D. L., \& Tucker, I. (2013). Mapping knowledge space and technological relatedness in US cities. European Planning Studies, 21, 1374-1391. doi:10.1080/09654313.2012.755832

Kogler, D. F., \& Whittle, A. (2018). The geography of knowledge creation: Technological relatedness and regional smart specialization strategies. In A. Paasi, J. Harrison, \& M. Jones (Eds.), Handbook on the geographies of regions and territories (pp. 153-168). Cheltenham: Edward Elgar. doi:10.4337/9781785365805.00022

Levin, R. C., Klevorick, A. K., Nelson, R. R., \& Winter, S. G. (1987). Appropriating the returns from industrial research and development. Brookings Papers on Economic Activity, 1987, 783-820. doi:10.2307/2534454

Leydesdorff, L., \& Bornmann, L. (2012). Mapping (USPTO) patent data using overlays to google maps. Journal of the American Society for Information Science and Technology, 63(7), 14421458. doi:10.1002/asi.22666

Leydesdorff, L., Etzkowitz, H., \& Kushnir, D. (2016). Globalization and growth of U.S. University patenting (2009-2014). Industry and Higher Education, 30(4), 257-266. doi:10.1177/ 0950422216660253

Leydesdorff, L., Heimeriks, G., \& Rotolo, D. (2016). Journal portfolio analysis for countries, cities, and organizations: Maps and comparisons. Journal of the Association for Information Science and Technology, 67(3), 741-748. doi:10.1002/asi.23551

Leydesdorff, L., Kogler, D. F., \& Yan, B. (2017). Mapping patent classifications: Portfolio and statistical analysis, and the comparison of strengths and weaknesses. Scientometrics, 112(3), 15731591. doi:10.1007/s11192-017-2449-0

Leydesdorff, L., Kushnir, D., \& Rafols, I. (2014). Interactive overlay maps for US patent (USPTO) data based on international patent classification (IPC). Scientometrics, 98(3), 1583-1599. doi:10. 1007/s11192-012-0923-2

Lundvall, B.-Å. (1988). Innovation as an interactive process: from user-producer interaction to the national system of innovation. In G. Dosi, C. Freeman, R. Nelson, G. Silverberg, \& L. Soete (Eds.), Technical change and economic theory (pp. 349-369). London: Pinter.

Maisonobe, M., Eckert, D., Grossetti, M., Jégou, L., \& Milard, B. (2016). The world network of scientific collaborations between cities: Domestic or international dynamics? Journal of Informetrics, 10(4), 1025-1036. doi:10.1016/j.joi.2016.06.002

Martin, R., \& Sunley, P. (2006). Path dependence and regional economic evolution. Journal of Economic Geography, 6, 395-437. doi:10.1093/jeg/lbl012

McCann, P., \& Ortega-Argilés, R. (2015). Smart specialization, regional growth and applications to European Union cohesion policy. Regional Studies, 49(8), 1291-1302. doi:10.1080/00343404. 2013.799769 
Mellander, C., \& Florida, R. (2016). The city as innovation machine. Regional Studies, 51(1), 86-96.

Morgan, K. (1997). The learning region: Institutions, innovation and regional renewal. Regional Studies, 31(5), 491-503. doi:10.1080/00343409750132289

Morgan, K. (2015). Smart specialisation: Opportunities and challenges for regional innovation policy. Regional Studies, 49(3), 480-482. doi:10.1080/00343404.2015.1007572

Narin, F. (1976). Evaluative bibliometrics: The use of publication and citation analysis in the evaluation of scientific activity. Washington, DC: National Science Foundation.

Nelson, R. (Ed.). (1993). National innovation systems: A comparative analysis. Oxford: Oxford University Press.

Nelson, R., \& Winter, S. G. (1982). An evolutionary theory of economic change. Cambridge, MA: The Belknap Press.

Nomaler, Ö., Frenken, K., \& Heimeriks, G. (2014). On scaling of scientific knowledge production in U.S. Metropolitan areas. PLoS ONE, 9(10), e110805. doi:10.1371/journal.pone.0110805

OECD. (2009). OECD patent statistics manual. Report. Paris: OECD.

Pavitt, K. (1985). Patent statistics as indicators of innovative activities: Possibilities and problems. Scientometrics, 7, 77-99. doi:10.1007/BF02020142

Popp, D., Juhl, T., \& Johnson, D. K. N. (2003). Determinants of the grant lag for U.S. Patent applications (NBER Working Paper No. 9518), pp. 1-50.

Rafols, I., \& Meyer, M. (2010). Diversity and network coherence as indicators of interdisciplinarity: Case studies in bionanoscience. Scientometrics, 82(2), 263-287. doi:10.1007/ s11192-009-0041-y

Rafols, I., Porter, A., \& Leydesdorff, L. (2010). Science overlay maps: A new tool for research policy and library management. Journal of the American Society for Information Science and Technology, 61(9), 1871-1887. doi:10.1002/asi.21368

Rao, C. R. (1982). Diversity: Its measurement, decomposition, apportionment and analysis. Sankhy: The Indian Journal of Statistics, Series A, 44(1), 1-22.

Ricotta, C., \& Szeidl, L. (2006). Towards a unifying approach to diversity measures: Bridging the gap between the Shannon entropy and Rao's quadratic index. Theoretical Population Biology, 70(3), 237-243. doi:10.1016/j.tpb.2006.06.003

Rigby, D. (2015). Technological relatedness and knowledge space: Entry and exit of US cities from patent classes. Regional Studies, 49(11), 1922-1937. doi:10.1080/00343404.2013.854878

Romer, P. M. (1994). The origins of endogenous growth. Journal of Economic Perspectives, 8(1), 3-22. doi:10.1257/jep.8.1.3

Rotolo, D., Rafols, I., Hopkins, M. M., \& Leydesdorff, L. (2017). Strategic intelligence on emerging technologies: Scientometric overlay mapping. Journal of the Association for Information Science and Technology, 68(1), 214-233. doi:10.1002/asi.23631

Scherer, F. M. (1984). Innovation and growth: Schumpeterian perspectives. Cambridge, MA: MIT Press.

Scheu, M., Veefkind, V., Verbandt, Y., Galan, E. M., Absalom, R., \& Förster, W. (2006). Mapping nanotechnology patents: The EPO approach. World Patent Information, 28, 204-211. doi:10. 1016/j.wpi.2006.03.005

Schumpeter, J. (1943). Socialism, capitalism and democracy. London: Allen \& Unwin.

Small, H., \& Garfield, E. (1985). The geography of science: Disciplinary and national mappings. Journal of Information Science, 11(4), 147-159. doi:10.1177/016555158501100402

Stirling, A. (2007). A general framework for analysing diversity in science, technology and society. Journal of the Royal Society Interface, 4(15), 707-719. doi:10.1098/rsif.2007.0213

Van Eck, N. J., \& Waltman, L. (2010). Software survey: VOSviewer, a computer program for bibliometric mapping. Scientometrics, 84(2), 523-538. doi:10.1007/s11192-009-0146-3

Van Zeebroeck, N. (2011). The puzzle of patent value indicators. Economics of Innovation and New Technology, 20, 33-62. doi:10.1080/10438590903038256

Van Zeebroeck, N., \& Van Pottelsberghe de la Potterie, B. (2011). The vulnerability of patent value determinants. Economics of Innovation and New Technology, 20, 283-308. doi:10.1080/ 10438591003668638 
Veefkind, V., Hurtado-Albir, J., Angelucci, S., Karachalios, K., \& Thumm, N. (2012). A new EPO classification scheme for climate change mitigation technologies. World Patent Information, 34 (2), 106-111. doi:10.1016/j.wpi.2011.12.004

Wallace, M. L., \& Rafols, I. (2015). Research portfolio analysis in science policy: Moving from financial returns to societal benefits. Minerva, 53(2), 89-115. doi:10.1007/s11024-015-9271-8

Yan, B., \& Luo, J. (2017). Measuring technological distance for patent mapping. Journal of the Association for Information Science and Technology, 68(2), 423-437. doi:10.1002/asi.23664

Zhang, L., Rousseau, R., \& Glänzel, W. (2011). Document-type country profiles. Journal of the American Society for Information Science and Technology, 62(7), 1403-1411. doi:10.1002/asi. 21537

Zhang, L., Rousseau, R., \& Glänzel, W. (2016). Diversity of references as an indicator for interdisciplinarity of journals: Taking similarity between subject fields into account. Journal of the American Society for Information Science and Technology, 67(5), 1257-1265. doi: 10.1002/asi. 23487

\section{Appendix I}

\section{Portfolio analysis and maps in terms of patent classes}

1. Preparing input files

a. Download the following files from https://leydesdorff.net/software/patents/ into a single folder:

- ipc.exe;

- ipc.dbf (with basis information about the classes);

- uspto1.exe (needed for the downloading of USPTO patents);

- cos_ipc3.dbf and cos_ipc4.dbf (needed for the computation of distances on the map);

b. Run ipc.exe.

2. Options within ipc.exe

a. The programme asks for a short name ( $\leq 10$ characters) in each run. This name will be used as the variable name in later parts of the routine;

b. The first option is to download the patents from USPTO at http://patft.uspto.gov/ netahtml/PTO/search-adv.htm; detailed instructions for the downloading can be found at http://www.leydesdorff.net/ipcmaps;

c. USPTO has a maximum of 1000 records at a time; but one is allowed to follow-up batches; after each download, save the files in another folder or as a zip file;

3. The incremental construction of the files matrix.dbf and rao.dbf

a. After each run, a column variable is added to the (local) file matrix.dbf containing the distribution of the $630 \mathrm{CPC} / \mathrm{IPC}$ classes in the document set under study. If the file matrix.dbf is absent, it is generated de novo and the current run is considered as generating the first variable; matrix.dbf can be read by Excel, SPSS, etc., for further (statistical) analysis;

b. Similarly, a row variable is added after each run to the file rao.dbf containing diversity measures (explained in the article) as variables. This file is also de novo generated if previously absent. Distances are based on $[1-\cos (x, y)]$ for each two distributions $\mathbf{x}$ and $\mathbf{y}$;

c. The routine ipc2cos.exe reads the file matrix.dbf and produces cosine.net and coocc.dat as (normalized) co-occurrence matrices that can be used in network analysis and visualization programmes such as Pajek or UCInet.

4. Output files in each run

a. Two files (vos3.txt and vos4.txt) are generated for mapping the portfolio at the three- or four-digit level of CPC/IPC, respectively, using VOSviewer; the distances and colours (corresponding to clusters) in the maps are based on the base-map (Leydesdorff et al., 2014); 
b. The further files ipc3.vec and ipc4.vec can be used as vectors in Pajek files. This allows for layouts other than VOSviewer and for more detailed network analysis and statistics; the files ipc3.cls and ipc4.cls are so-called cluster files which can be used in Pajek, among other things, for the extraction of the local maps at the respective levels.

c. The various fields in the USPTO records are organized in a series of databases that can be related (e.g. in MS Access) using the field 'nr'. 